\title{
St Jude Medical Epic porcine bioprosthesis: Results of the regulatory evaluation
}

\author{
W. R. Eric Jamieson, MD, ${ }^{\mathrm{a}}$ Clifton T. P. Lewis, MD, ${ }^{\mathrm{b}}$ Marc P. Sakwa, MD, ${ }^{\mathrm{c}}$ Denton A. Cooley, MD, \\ Vibhu R. Kshettry, MD, ${ }^{\mathrm{e}}$ Kent W. Jones, MD, ${ }^{\mathrm{f}}$ Tirone E. David, MD, ${ }^{\mathrm{g}}$ John A. Sullivan, MD, ${ }^{\mathrm{h}}$ \\ Guy J. Fradet, MD, ${ }^{\mathrm{a}}$ and David S. Bach, MD ${ }^{\mathrm{i}}$
}

\begin{abstract}
Background: The St Jude Medical Epic heart valve (St Jude Medical, Inc, St Paul, Minn) is a tricomposite glutaraldehyde-preserved porcine bioprosthesis. The St Jude Medical Biocor porcine bioprosthesis is the precursor valve to the St Jude Medical Epic valve. The Epic valve is identical to the Biocor valve except that it is treated with Linx AC ethanol-based calcium mitigation therapy.
\end{abstract}

Methods: The St Jude Medical Epic valve was implanted in 761 patients (mean age $73.9 \pm 9.2$ years) between 2003 and 2006 in the US Food and Drug Administration regulatory study in 22 investigational centers. The position distribution was 557 aortic valve replacements, 175 mitral valve replacements, and 29 double valve replacements. Concomitant coronary artery bypass grafting was performed in $50.8 \%$ of patients undergoing aortic valve replacement and $36.6 \%$ of those undergoing mitral valve replacement.

Results: The early mortality was $3.6 \%$ in aortic and $2.3 \%$ in mitral valve replacement. The follow-up was 1675.5 patient-years with a mean of $2.2 \pm 1.2$ years/patient. Late mortality was $5.2 \% /$ patient-year in aortic and $6.6 \%$ patient-year in mitral valve replacement. The late major thromboembolism rate was $0.98 \% / \mathrm{pa}$ tient-year for aortic and 2.6\%/patient-year for mitral valve replacement. There were 19 reoperations, including 2 for structural valve deterioration, 1 for thrombosis, 9 for nonstructural dysfunction, and 7 for prosthetic valve endocarditis. The actuarial freedom from reoperation owing to structural valve deterioration for aortic valve replacement at 4 years for age 60 years or less was $93.3 \% \pm 6.4 \%$; for ages 61 to 70 years, $98.1 \% \pm 1.9 \%$; and for older than 70 years, $100 \%(P=.0006>70 \mathrm{vs} \leq 60$ years $)$. There were no events of structural deterioration with mitral valve replacement. The actuarial freedom from major thromboembolism for all patients at 4 years was $93.6 \% \pm 1.0 \%$. The 2 cases of structural valve deterioration occurred in aortic valves that became perforated without calcification causing aortic regurgitation.

Conclusions: The performance of the St Jude Medical Epic porcine bioprosthesis is satisfactory at 4 years for both aortic and mitral valve replacement. This study establishes the early clinical performance including durability of this porcine bioprosthesis. (J Thorac Cardiovasc Surg 2011;141:1449-54)

Supplemental material is available online.

The quest to establish a bioprosthesis for cardiac valve replacement that is durable for 20 to 25 years continues. There are current reports of 18 - to 20-year valve durability experience with porcine and pericardial bioprostheses. ${ }^{1-3}$ Of these, the St Jude Medical Biocor porcine bioprosthesis (St Jude Medical, Inc, St Paul, Minn) has a long-term durabil-

\footnotetext{
From University of British Columbia, ${ }^{a}$ Vancouver, British Columbia, Canada; Sarasota Memorial Hospital, ${ }^{\mathrm{b}}$ Sarasota, Fla; William Beaumont Hospital, ${ }^{\mathrm{c}}$ Royal Oak, Mich; Texas Heart Institute at St. Luke's Episcopal Hospital, ${ }^{\mathrm{d}}$ Houston, Tex; Abbott Northwestern Hospital, ${ }^{\mathrm{e}}$ Minneapolis, Minn; Intermountain Medical Centre, ${ }^{\mathrm{f}}$ Salt Lake City, Utah; Toronto General Hospital, ${ }^{\mathrm{g}}$ Toronto, Ontario, Canada; Queen Elizabeth II Health Sciences Centre, ${ }^{\mathrm{h}}$ Halifax, Nova Scotia, Canada; and Ann Arbor, ${ }^{i}$ Mich.

Disclosures: W. R. Eric Jamieson is a consultant to St Jude Medical Inc, as well as a consultant or member of the speakers' bureau for other prosthetic valve manufacturers, inclusive of Medtronic Inc, Sorin Group, Edwards Lifesciences, and OnX Life Technologies Inc. David S. Bach reports consulting fees for CVRx, Edwards Lifesciences, Medtronic, and St Jude Medical, as well as lecture fees from Edwards Lifesciences and Medtronic. Clifton T. P. Lewis reports consulting and proctoring fees from St Jude Medical, Intuitive Surgical, and St Jude medical.
}

ity record. ${ }^{1}$ The same valve, with an ethanol-based anticalcification treatment, Linx AC, is the St. Jude Medical Epic bioprosthesis. Both valves are tricomposite porcine bioprostheses formulated with 3 individual, independent porcine leaflets. Both include a low-profile flexible stent with a pericardial shield designed to aid in valve durability providing a tissue-to-tissue contact when the valve opens and closes.

The St Jude Medical Epic porcine bioprosthesis was evaluated in a Food and Drug Administration investigational device exemption study conducted between 2003 and 2006 at 22

Kent W. Jones reports consulting fees from St Jude Medical. Guy J. Fradet reports consulting fees from Medtronic and lecture fees from Sorin Medical. Tirone E. David, Marc P. Sakwa, John A. Sullivan, Denton A. Cooley, and Vibhu R. Kshettry have no commercial interests to disclose.

Presented to the Society for Heart Valve Disease, Berlin, Germany, June 27-30, 2009.

Received for publication Feb 23, 2010; revisions received April 29, 2010; accepted for publication May 17, 2010; available ahead of print Jan 31, 2011.

Address for reprints: W. R. Eric Jamieson MD, Vancouver General Hospital, \#3500 -

2700 Jim Pattison Pavilion, 855 West 12th Ave, Vancouver, BC V5Z 1M9, Canada

(E-mail: eric.jamieson@vch.ca).

0022-5223/\$36.00

Copyright (c) 2011 by The American Association for Thoracic Surgery doi:10.1016/j.jtcvs.2010.05.055 


\section{Abbreviations and Acronyms \\ $\mathrm{AVR}=$ aortic valve replacement \\ $\mathrm{LV}=$ left ventricular \\ MVR $=$ mitral valve replacement \\ $\mathrm{SVD}=$ structural valve deterioration}

investigational centers in the United States and Canada. Since Biocor was introduced in 1981, multiple investigative groups have reported on extended experience in the past 4 years. ${ }^{1,4,5}$ Two reports on mitral replacement populations have identified remarkable durability performance in patients averaging just under 50 years of age. ${ }^{5,6}$ The durability performance of the Epic aortic and mitral bioprostheses has been reported in a large 5-year study in an elderly population over 75 years of age. ${ }^{7}$

This study establishes the early performance in a prospective evaluation of a large patient population and affords the opportunity for extended evaluation.

\section{METHODS}

This evaluation incorporated the methodology detailed in the "Guidelines for Reporting Morbidity and Mortality after Cardiac Valvular Operations (Valve Interventions) ${ }^{, 8,9}$ and the requirements of the US Food and Drug Administration for an investigational device exemption study. Where there was variance, especially with regard to the definition of hemorrhage, only antithrombotic hemorrhage was reported in this study. Anticoagulation management was at the discretion of the standards of care of the respective institutions.

The bioprosthesis was implanted in 761 patients (women $43.9 \%$, men $56.1 \%$ ) from 2003 to 2006 . The mean age of the population was $73.9 \pm$ 9.2 years, with a range of 24 to 93 years. There were 557 aortic (AVR), 175 mitral (MVR), and 29 double valve replacements. Of the patients in the AVR group, 34 were less than 60 years of age, 101 were between 61 to 70 years, and 422 were older than 70 years. In the MVR population, 17 were younger than 60 years, 47 were between 61 and 70 years, and 111 were older than 70 years. The patient characteristics of the AVR and MVR populations are detailed in Table 1 . The populations were distinguished for gender, left atrial enlargement, pulmonary hypertension, congestive heart failure, cardiac arrhythmias, left ventricular (LV) dysfunction, and mitral valve repair $(P<.0001)$.

Previous surgery had been performed in $23.3 \%$ of AVR and $31.4 \%$ of MVR patients. Concomitant coronary artery bypass grafting was conducted in $50.8 \%$ of AVR and $36.6 \%$ of MVR patients. Concomitant atrial fibrillation ablation was performed in $5.4 \%$ of AVR and $23.4 \%$ of MVR patients; the procedures were performed with surgical, radiofrequency, or cryotherapy ablation.

Principal investigators from 8 of the study centers were selected to report on all data from the 22 investigational North American centers. The study centers and respective study principal investigators are shown in Appendix 1. These principal investigators were chosen on overall implant population of the various centers. The enrolment in the study closed in March 2006. The follow-up incorporated 1675.5 patient-years with a mean of $2.2 \pm$ 1.2 years per patient. The completeness of follow-up was $97.2 \%$ at 2 years and $94.9 \%$ at 4 years for AVR and $96.6 \%$ at 2 years and $94.8 \%$ at 4 years for MVR. The echocardiographic evaluation was complete for AVR at 6 months, 1 year, and 2 years in $93.4 \%, 93.5 \%$, and $89.1 \%$ of the patients, and for MVR at 6 months, 1 year, and 2 years in $91.4 \%, 94.2 \%$, and $89.7 \%$ of the patients. The follow-up was conducted at the investigating cen- ters by clinic evaluation, primary physician assessment or, if necessary, telephone interviews and attainment of appropriate documentation. The followup occurred at 6 months, 1 year, and annually. The evaluation included echocardiograms and blood assessment (inclusive of haptoglobin and serum lactate dehydrogenase), as well as New York Heart Association functional classification, medications, and documentation of any adverse events.

The statistical analyses were performed with SAS software (version 9.1.3; SAS Institute, Inc, Cary, NC). Descriptive summaries are expressed as mean values for continuous variables and as percentage for categorical variables; $P$ values are from 2-sample $t$ test or $\chi^{2}$ test as appropriate. Late adverse event rates (percent per patient-year) are expressed as a linearized rate ([the number of late events occurring 31 or more days after implant/total late patient-years calculated for each subject from 31 days after implant to the last contact] - 100). Kaplan-Meier analyses are performed for survival or freedom from the event rates, and groups are compared using the log-rank static. Only Kaplan-Meier actuarial data analysis was reported because of the objective to report on prosthesis performance and not performance in a specific population subset (cumulative incidence, actual analysis).

\section{RESULTS}

The early mortality (30-day mortality) was $3.6 \%$ (20 events) for AVR and $2.3 \%$ ( 4 events) for MVR. The occurrence of the predominant valve-related complications presented as linearized occurrence rates (percent per patient-year) and actuarial freedom at 4 years for both AVR and MVR populations are detailed in Table 2 with the corresponding events. The valve-related mortality for AVR was $0.4 \%$ /patient-year and for MVR it was 1.1\%/patient-year. The major thromboembolism rates, inclusive of major cerebrovascular accident and reversible ischemic neurologic deficit, were $0.98 \%$ /patient-year (12 events) and 2.6\%/patient-year (9 events), respectively, for AVR and MVR. The antithrombotic hemorrhage rates were $1.3 \%$ /patient-year (16 events) for AVR and $1.7 \%$ patient-year (6 events) for MVR.

There were 9 late valve-related deaths occurring between 83 and 1080 days after implantation (prosthetic valve endocarditis $=2$; periprosthetic leak $=1$; hemorrhage $=2$; and sudden unexplained/unexpected $=4$ ). There was only 1 reoperation (prosthetic valve endocarditis); the patient died during the reoperation for double valve replacement. There were 21 cases of cerebrovascular accident/reversible ischemic neurologic deficit (AVR $=12$ and MVR $=9)$. Eight patients had documented accompanying atrial fibrillation. There were 2 cases of MVR thrombosis, only 1 requiring reoperation. The additional case was managed conservatively with anticoagulation.

Table 3 documents the actuarial performance of reoperation of the overall events, as well as the events in each valverelated complication category. There were 21 overall reoperative events including 1 heart transplantation and 1 early reoperation for atrioventricular groove disruption. All patients had successful surgery. Two patients required reoperation for structural valve deterioration (SVD). Both had had AVR, aged 47 and 61 years at implant, with the finding of perforation(s) not associated with calcification and presented with aortic regurgitation. 
TABLE 1. Patient population and medical history*

\begin{tabular}{|c|c|c|c|}
\hline Variables & $\operatorname{AVR}(n=557)$ & $\operatorname{MVR}(\mathbf{n}=\mathbf{1 7 5})$ & $P$ value \\
\hline Age (y) & $74.4 \pm 9.3(24.6,93.3)$ & $72.2 \pm 8.9(44.5,91.4)$ & .0054 \\
\hline Gender (male) & $61.0 \%(340)$ & $44.0 \%(77)$ & $<.0001$ \\
\hline NYHA III/IV & $55.5 \%(309)$ & $61.7 \%(108)$ & .1459 \\
\hline Systemic hypertension & $76.5 \%(426)$ & $69.1 \%(121)$ & .0513 \\
\hline Left atrial enlargement & $23.9 \%(133)$ & $42.9 \%(75)$ & $<.0001$ \\
\hline Diabetes mellitus & $26.2 \%(146)$ & $20.0 \%$ & .0966 \\
\hline TIA & $6.3 \%(35)$ & $3.4 \%(6)$ & .1519 \\
\hline Stroke/RIND/CVA & $6.6 \%(37)$ & $6.9 \%(12)$ & .9211 \\
\hline Pulmonary hypertension & $14.2 \%(79)$ & $34.9 \%(61)$ & $<.0001$ \\
\hline Myocardial infarction & $13.1 \%(73)$ & $16.6 \%(29)$ & .2482 \\
\hline Congestive heart failure & $36.3 \%(202)$ & $57.1 \%(100)$ & $<.0001$ \\
\hline Hyperlipidemia & $59.8 \%(333)$ & $45.7 \%(80)$ & .0011 \\
\hline Cancer & $19.9 \%(111)$ & $19.4 \%(34)$ & .8850 \\
\hline Lung disease & $21.2 \%(118)$ & $18.3 \%(32)$ & .4072 \\
\hline Coronary artery disease & $65.0 \%(362)$ & $49.7 \%(87)$ & .0003 \\
\hline Carotid artery disease & $12.7 \%(71)$ & $6.9 \%(12)$ & .0321 \\
\hline Peripheral vascular disease & $14.0 \%(78)$ & $7.4 \%(13)$ & .0215 \\
\hline Endocarditis & $1.4 \%(8)$ & $2.9 \%(5)$ & .2144 \\
\hline Cardiac arrhythmias & $26.0 \%(145)$ & $46.9 \%(82)$ & $<.0001$ \\
\hline Renal failure & $3.8 \%(21)$ & $4.0 \%(7)$ & .8900 \\
\hline LV dysfunction & $66.8 \%(372)$ & $46.9 \%(82)$ & $<.0001$ \\
\hline RV dysfunction & $0.5 \%$ & $2.3 \%(4)$ & .0383 \\
\hline $\mathrm{AV}$ repair or replacement & $0.9 \%(5)$ & $0.0 \%(0)$ & .2085 \\
\hline MV repair & $0.2 \%$ & $7.4 \%(13)$ & $<.0001$ \\
\hline Previous CABG & $8.1 \%(45)$ & $6.3 \%(11)$ & .4362 \\
\hline Previous carotid endarterectomy & $4.3 \%(24)$ & $2.9 \%(5)$ & .3905 \\
\hline Previous pacemaker & $6.1 \%(34)$ & $6.9 \%(12)$ & .7203 \\
\hline Balloon annuloplasty & $2.7 \%(15)$ & $2.3 \%$ & .7675 \\
\hline Other surgery & $7.5 \%(42)$ & $16.0 \%(28)$ & .0009 \\
\hline \multicolumn{4}{|l|}{ Valve dysfunction } \\
\hline Insufficiency & $9.7 \%(54)$ & $69.1 \%(121)$ & $<.0001$ \\
\hline Stenosis & $62.7 \%(349)$ & $8.6 \%(15)$ & $<.0001$ \\
\hline Mixed & $27.6 \%(154)$ & $21.7 \%(38)$ & .1196 \\
\hline Not reported & $0.0 \%(0)$ & $0.6 \%(1)$ & .2391 \\
\hline
\end{tabular}

$A V R$, Aortic valve replacement; $M V R$, mitral valve replacement; $N Y H A$, New York Heart Association; TIA, transient ischemic attack; RIND, reversible ischemic neurologic deficit; $C V A$, cerebrovascular accident; $L V$, left ventricular; $R V$, right ventricular; $A V$, aortic valve; $M V$, mitral valve; $C A B G$, coronary artery bypass grafting. *A subject can be counted in multiple categories based on his or her individual medical history.

The pathologic evaluation of the 2 cases of SVD has identified abnormal findings of the native porcine leaflets, resulting in perforations and tears:

The examining pathologist in the initial case concluded that 2 of the cusps showed deterioration of the cuspal collagen and increasing permeability of the cusps with fibrin permeation resulting in cuspal perforation. One of the cusps had an accompanying tear. The third cusp had focal areas of thinning of the cuspal fibrosa. There was no evidence of endocarditis or calcification.

The examining pathologist in the second case found that all 3 leaflets contained attenuation of the fibrosa and fibrin permeation of the spongiosa. Two leaflets had small perforations identical to each other near the free edges and the

TABLE 2. Valve-related late complications

\begin{tabular}{lccccc}
\hline & \multicolumn{2}{c}{ AVR } & & \multicolumn{2}{c}{ MVR } \\
\cline { 2 - 5 } & $\begin{array}{c}\text { Late complications, } \\
\% / \mathbf{p t}-\mathbf{y}(\mathbf{n})\end{array}$ & $\begin{array}{c}\text { KM freedom from } \\
\text { the event, \% at 4 y }\end{array}$ & & $\begin{array}{c}\text { Late complications, } \\
\% / \mathbf{p t}-\mathbf{y}(\mathbf{n})\end{array}$ & $\begin{array}{c}\text { KM freedom from } \\
\text { the event, \% at 4 y }\end{array}$ \\
\hline Valve-related mortality & $0.4(5)$ & $98.7 \% \pm 0.6 \%$ & $1.1(4)$ & $96.6 \% \pm 1.5 \%$ \\
Major TE (CVA + RIND) & $0.98(12)$ & $94.5 \% \pm 1.2 \%$ & $2.6(9)$ & $91.0 \% \pm 2.5 \%$ \\
Thrombosis & $0.0(0)$ & $100 \% \pm 0.0 \%$ & & $0.6(2 *)$ & $97.9 \% \pm 1.6 \%$ \\
\hline
\end{tabular}

$A V R$, Aortic valve replacement; $M V R$, mitral valve replacement; $K M$, Kaplan-Meier; $T E$, thromboembolism; $C V A$, cerebrovascular accident; RIND, reversible ischemic neurologic deficit. *One subject had echocardiographic evidence of possible small thrombosis that resolved on anticoagulant management. 
TABLE 3. Summary of freedom from reoperation for valve-related complications

\begin{tabular}{lcc}
\hline Reoperation & Freedom & Events \\
\hline Overall & $92.3 \% \pm 2.3 \%$ & $21 \%$ \\
Valve related & $92.6 \% \pm 2.3 \%$ & 19 \\
SVD & $99.4 \% \pm 0.4 \%$ & 2 \\
NSD & $97.2 \% \pm 1.4 \%$ & 9 (PPL 6) \\
PVE & $96.2 \% \pm 1.9 \%$ & 7 \\
Thrombosis & $99.7 \% \pm 0.3 \%$ & 1 \\
\hline
\end{tabular}

$S V D$, Structural valve deterioration; $N S D$, nonstructural dysfunction; $P P L$, periprosthetic leak; $P V E$, prosthetic valve endocarditis. *Heart transplantation, $\mathrm{n}=1$; atrioventricular disruption, $\mathrm{n}=1$.

other leaflet had a linear tear. There was no evidence of endocarditis or calcification.

Prosthetic valve endocarditis requiring reoperation occurred in 7 cases. One case of mitral valve thrombosis required reoperation in a patient with a history of endocarditis. The remainder of events were due to nonstructural dysfunction including 2 cases of pannus, 6 cases of paravalvular leaks, and 1 case of dehiscence of the aortomitral annular continuity requiring surgical repair.

The overall survival of the total population was $76.0 \% \pm$ $2.7 \%$ at 4 years. Figures E1 and E2 illustrate survival by age groups (group A $\leq 60$, group B 61-70, and group C $>70$ years) for the AVR and MVR populations. For AVR, survival for group B (61-70 years) was greater than for group $\mathrm{C}(>70$ years) $(P=.013)$, and survival for group A ( $\leq 60$ years) was greater than for group $\mathrm{C}(>70$ years) $(P=.011)$. There was no significant difference between groups A and B ( $<60$ years and $61-70$ years; $P=.076)$. Survival after MVR was not different by age groups $(P=.145)$, but the patient populations were small for the younger groups.

The actuarial freedom from valve-related mortality for the overall population was $98.1 \% \pm 0.6 \%$ at 4 years and for all-cause reoperation, $92.3 \% \pm 2.3 \%$ at 4 years (Table 3). The actuarial freedom from valve-related reoperation was $92.6 \% \pm 2.3 \%$ at 4 years (Table 3 ).

The actuarial freedom from reoperation owing to SVD for the overall population at 4 years was $99.4 \% \pm 0.4 \%$ (Table 3); for AVR 99.2\% $\pm 0.6 \%$ and for MVR $100 \%$. The actuarial freedom from reoperation owing to SVD for AVR age groups is illustrated in Figure 1. The freedom at 4 years for group $\mathrm{A}$ ( $\leq 60$ years) was $93.3 \% \pm 6.4 \%$; for group B (61-70 years), $98.1 \% \pm 1.9 \%$; and for group C ( $>70$ years), $100 \%$. The actuarial freedom from reoperation owing to SVD for MVR age groups is presented in Figure 2. The freedom for each of the age groups (overall MVR range $44-91$ ) is $100 \%$ at 4 years.

The actuarial freedom from overall thromboembolism at 4 years was $90.0 \% \pm 1.7 \%$. The freedom from major thromboembolism and reversible ischemic neurologic deficit at 4 years was $93.6 \% \pm 1.0 \%$. The freedom from antithrombotic hemorrhage at 4 years was $90.7 \% \pm 1.2 \%$ and
Freedom (Actuarial) - Reoperation due to SVD $\leq 60,61-70,>70 y r s$ for AVR

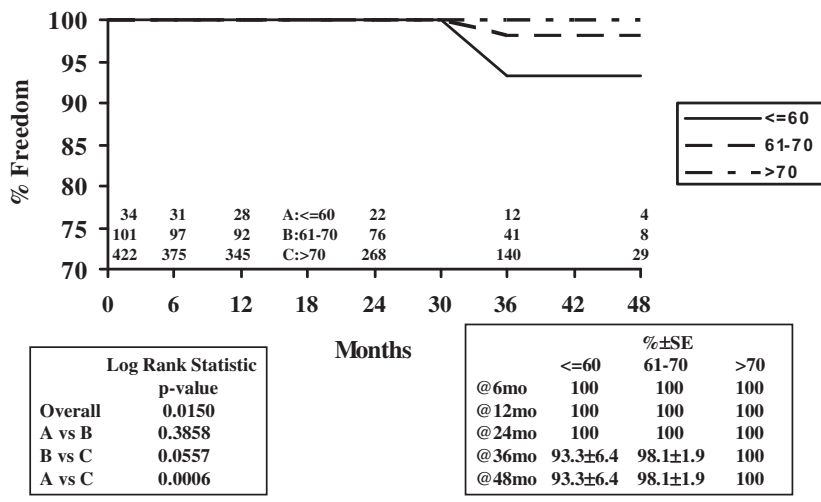

FIGURE 1. Freedom from reoperation owing to SVD for AVR by age groups $(\leq 60,61-70,>70$ years). $S V D$, Structural valve deterioration; $A V R$, aortic valve replacement.

from thrombosis, $99.6 \% \pm 0.3 \%$. (The freedom from reoperation owing to thrombosis was $99.7 \% \pm 0.3 \%$.)

The actuarial freedom from overall reoperation for prosthetic valve endocarditis at 4 years was $96.2 \% \pm 1.9 \%$ (Table 3). For the same time interval, the actuarial freedom from reoperation owing to nonstructural dysfunction, inclusive of periprosthetic leak, was $97.2 \% \pm 1.4 \%$ (Table 3 ).

The hemodynamic performance at 6 months and 2 years for AVR and MVR is illustrated in Figures E3 and E4. The size distributions for AVR were as follows: $21 \mathrm{~mm}, 17.2 \%$; $23 \mathrm{~mm}, 37.0 \%$; $25 \mathrm{~mm}, 33.8 \%$; $27 \mathrm{~mm}, 10.2 \%$; and $29 \mathrm{~mm}, 1.7 \%$. For the mitral valve they were as follows: $25 \mathrm{~mm}, 4.4 \%$; $27 \mathrm{~mm}, 20.1 \%$; $29 \mathrm{~mm}, 38.7 \%$; $31 \mathrm{~mm}$, $21.1 \%$; and $33 \mathrm{~mm}, 15.7 \%$. The mean gradients and effective orifice areas for both positions are documented. There was no occurrence greater than mild insufficiency observed for the reoperation subjects, and prosthesis insufficiency was not found to be an issue for these subjects.

Freedom (Actuarial) - Reoperation due to SVD $\leq 60,61-70,>70 \mathrm{yrs}$ for MVR

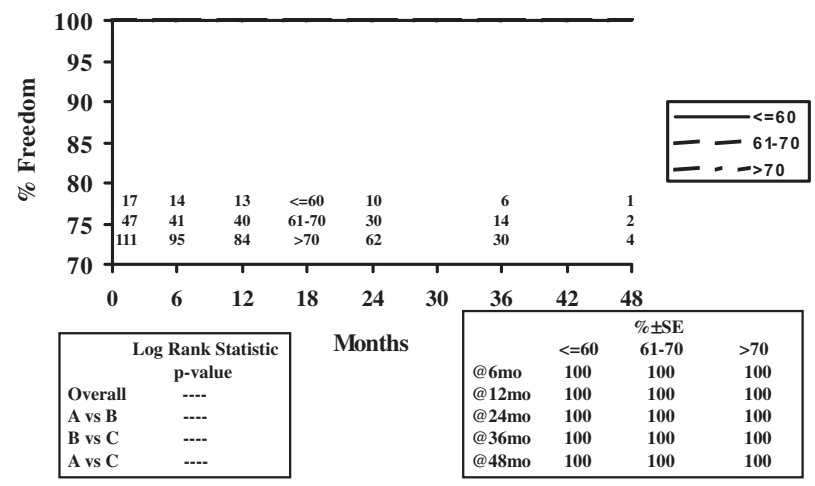

FIGURE 2. Freedom from reoperation owing to SVD for MVR by age groups $(\leq 60,61-70,>70$ years). $S V D$, Structural valve deterioration; $M V R$, mitral valve replacement. 
A total of 334 subjects with AVR had complete time points (discharge, 6 month, 1 year, and 2 year). LV mass index data were available for the analysis. The mean (average) LV mass index was reduced by $23.9 \mathrm{~g} / \mathrm{m}^{2}(P<.001)$ from discharge to 6 months, $26.8 \mathrm{~g} / \mathrm{m}^{2}(P=.0001)$ from discharge to 1 year, and $27.6 \mathrm{~g} / \mathrm{m}^{2}(P=.0001)$ from discharge to 2 years (Figure E5).

\section{DISCUSSION}

The St Jude Medical porcine bioprostheses have been evaluated in 5 publications since 2000. ${ }^{1,4-7}$ The Biocor bioprosthesis was introduced in Brazil in 1981 and performance over 20 years has been documented in 4 of these publications. St Jude Medical markets the Biocor porcine bioprosthesis worldwide. Biocor and Epic are the same bioprostheses except that Biocor is formulated with no calcium mitigation therapy whereas Epic is treated with Linx AC, an ethanol-based therapy for calcium mitigation. Both valves are tricomposite porcine bioprostheses with glutaraldehyde preservation at low-pressure conditions of less than $1 \mathrm{~mm} \mathrm{Hg}$. Midterm results of the Epic bioprosthesis aortic and mitral performance have been reported in 1 large series. ${ }^{7}$

The Biocor bioprosthesis has been reported by Mykén and Bech-Hansen ${ }^{1}$ in an AVR population of 70.8 years of age and an MVR population of 64.9 years. Eichinger and colleagues ${ }^{4}$ documented AVR performance in patients with a mean age of 72.5 years. Kirali, ${ }^{6}$ Pomerantzeff, ${ }^{5}$ and their coinvestigators documented MVR performance in populations with mean ages of 48 and 49.2 years, respectively. The reported experience on the Biocor and Epic prostheses have concentrated on freedom from valve-related mortality and freedom from SVD. They address durability of SVD primarily by explant reoperation. There are no comments on modes of failure in the reports on the Biocor bioprosthesis.

Before 2009, Mykén and colleagues reported on the Biocor bioprosthesis in 1994, 1995, 2000, and 2005. The recent report (2009) documented the 20-year performance of the Biocor valve in 1712 patients with $99.9 \%$ follow-up, mean follow-up of 6.0 years for AVR and 6.2 years for MVR. ${ }^{1}$ The 20 -year freedom from actuarial valve-related mortality was $84.3 \%$ for AVR and $88.0 \%$ for MVR. The actual/cumulative incidence of freedom from valve-related mortality was $92.5 \%$ for AVR and $92.8 \%$ for MVR. The 20-year freedom from reoperative SVD in AVR (1518 patients) was $61.1 \%$ (actual 85.6\%) and for MVR (194 patients), $79.3 \%$ (actual 91.2\%). The actuarial freedom in those older than 65 years and those 65 years or less for AVR was $92.1 \%$ and $44.5 \%$, respectively, and for MVR, $88.0 \%$ and $75.2 \%$, respectively. There were 77 subjects with SVD in the AVR by reoperative explant and 11 in the MVR group, for an overall rate of $0.9 \%$ /patient-year. The authors considered the durability of AVR and MVR to be comparable.
In 2008, Eichinger and coauthors ${ }^{4}$ reported on a cohort of 455 patients in whom the actuarial freedom from reoperative SVD after AVR was $86.5 \%$ at 20 years (mean of 8.2 years, completeness of $99.6 \%$ ). Three other reports had documented 20-year experience with aortic porcine and pericardial bioprostheses, but none of these publications has adequate numbers at risk beyond 15 to 18 years to provide adequate assessment of 20-year durability. ${ }^{2,10,11}$

The MVR durability, reported by Pomerantzeff and colleagues ${ }^{5}$ in 2006, in 546 patients (mean age 48 years) at 15 years was $51.8 \%$ for those younger than 50 years, $88.7 \%$ for those 51 to 60 years, and $84.0 \%$ for those 61 to 80 years for reoperative SVD. The freedom from valverelated mortality at 15 years was $80.7 \%$. Kirali and coinvestigators ${ }^{6}$ documented performance in 2001 for 158 patients. There were 39 SVD cases and 16 came to reoperation. The overall freedom from SVD at 13 years was $64.8 \%$ and for SVD reoperation, $76.8 \%$. The authors reported the 15 year freedom from valve-related mortality to be $98.6 \%$.

The performance of 1168 AVR and 101 MVR Epic valves implanted between 2001 and 2006, mean age of 76 years, provided 5 -year satisfactory results. ${ }^{7}$ In this report by Lehmann et al, ${ }^{7}$ the authors recommended long-term evaluation of the calcium-mitigation therapy.

In this current Epic study, we report on the regulatory population of 761 patients at 4 years: there were 2 AVR SVD cases of aortic insufficiency owing to cuspal perforations and actuarial freedom from reoperation owing to SVD for AVR at 4 years for ages 60 years and younger at $93.3 \% \pm 6.4 \%$; for ages 61 to 70 years at $98.1 \% \pm$ $1.9 \%$; and for older than 70 years at $100 \%(P=.0006>$ 70 vs $\leq 60$ years). There were no cases of MVR SVD. The mean follow-up was 2.2 years. The AVR SVD cases occurred in patients aged 47 and 61 years.

Hemodynamic performance was satisfactory for both MVR and AVR. All valves used were standard Epic aortic valves. The newer Epic Supra aortic valve is designed for supraannular implantation and provides the potential for improved hemodynamic performance. For the same tissue annulus diameter, the Epic Supra incorporates a larger stent and therefore has a larger stent/annulus ratio than does the Epic aortic. Regardless, in the current study, LV mass regression significantly improved in patients with sufficient follow-up data.

This study can serve as the basis for long-term durability and performance evaluation of the St Jude Medical Epic porcine bioprosthesis in both the aortic and mitral positions. This will be important to confirm the favorable durability considerations specifically for the mitral bioprosthesis.

\section{References}

1. Mykén PSU, Bech-Hansen O. A 20-year experience of 1712 patients with the Biocor porcine bioprosthesis. J Thorac Cardiovasc Surg. 2009;137:76-81.

2. Jamieson WR, Burr LH, Miyagishima RT, Germann E, MacNab JS, Stanford E, et al. Carpentier-Edwards supra-annular aortic porcine bioprosthesis: clinical performance over 20 years. J. Thorac Cardiovasc Surg. 2005;130:994-1000. 
3. Yankah CA, Pasic M, Musci M, Stein J, Detschades C, Siniawski H, et al. Aortic valve replacement with the Mitroflow pericardial bioprosthetic: durability results up to 21 years. J Thorac Cardiovasc Surg. 2008;136:688-96.

4. Eichinger WB, Hettich IM, Ruzicka DJ, Holper K, Schricker C, Blieziffer S, et al. Twenty-year experience with the St Jude Medical Biocor bioprosthesis in the aortic position. Ann Thorac Surg. 2008;86:1204-11.

5. Pomerantzeff PMA, Brandao CMA, Albuquerque JMCA, Stolf NAG, Grinberg M, Oliveira SA. Long-term follow up of the Biocor porcine bioprosthesis in the mitral position. J Heart Valve Dis. 2006;15:763-7.

6. Kirali K, Guler M, Tuncer A, Daglar B, Ipek G, Isik O, et al. Fifteen-year clinical experience with the Biocor porcine bioprostheses in the mitral position. Ann Thorac Surg. 2001;71:811-5.

7. Lehmann S, Walther T, Leontjev S, Kempfert J, Rastan A, Garbade J, et al. Midterm results after Epic Xenograft implantation for aortic, mitral, and double valve replacement. J Heart Valve Dis. 2007;16:641-8.
8. Edmunds LH Jr, Clark RE, Cohn LH, Grunkemeier GL, Miller DC, Weisel WD Guidelines for reporting morbidity and mortality after cardiac valvular operations. Ad Hoc Liaison Committee for Standardizing Definitions of Prosthetic Heart Valve Morbidity of The American Association for Thoracic Surgery and The Society of Thoracic Surgeons. J Thorac Cardiovasc Surg. 1996;112: 708-11.

9. Akins CW, Miller DC, Turina MI, Kouchoukos NT, Blackstone EH, Grunkemeier GL, et al. Guidelines for reporting mortality and morbidity after cardiac valve interventions. J. Thorac Cardiovasc Surg. 2008;135:732-8.

10. Borger MA, Ivanov J, Armstrong S, Christie-Hrybinsky D, Feindel CM, David TE. Twenty-year results of the Hancock II bioprosthesis. $J$ Heart Valve Dis. 2006;15:49-56.

11. Aupart MR, Mirza A, Meurisse YA, Sirinelli AL, Neville PH, Marchand MA. Perimount pericardial bioprosthesis for aortic calcified stenosis: 18-year experience with 1,133 patients. J Heart Valve Dis. 2006;15:768-76.

APPENDIX 1. Site principal investigator list

\begin{tabular}{|c|c|}
\hline Principal investigators & Investigational sites \\
\hline Monica McDonald, MD & St. Luke's Medical Center, Milwaukee, Wis \\
\hline Alfredo Trento, MD & Cedars-Sinai Medical Center, Los Angeles, Calif \\
\hline Vibhu Kshettry, MD & Abbott Northwestern Hospital, Minneapolis, Minn \\
\hline Alan Kypson, MD & East Carolina University, Greenville, NC \\
\hline J. Peter Murphy, MD & Missouri Baptist Medical Center, St. Louis, Mo \\
\hline Nora Burgess, MD & Kaiser Permanente Medical Center, San Francisco, Calif \\
\hline Clifton Lewis, MD & Sarasota Memorial Hospital, Sarasota, Fla \\
\hline Todd Shuman, MD & St Thomas Hospital, Nashville, Tenn \\
\hline Kent Jones, MD & Intermountain Medical Center, Salt Lake City, Utah \\
\hline John Puskas, MD & Emory University Hospital, Crawford Long Hospital, Atlanta, Ga \\
\hline Valluvan Jeevanandam, MD & The University of Chicago, Chicago, Ill \\
\hline Robert Mitchell, MD & Central Baptist Hospital, Lexington, Ky \\
\hline Paul Corso, MD & Washington Hospital Center, Washington, DC \\
\hline Marc Sakwa, MD & William Beaumont Hospital, Royal Oak, Mich \\
\hline Denton Cooley, MD & Texas Heart Institute at St. Luke's Episcopal Hospital, Houston, Tex \\
\hline John Oswalt, MD & Austin Heart Hospital, Seton Medical Center, Austin, Tex \\
\hline Michael Ingram, MD & Sutter Memorial Hospital, Sacramento, Calif \\
\hline A. Michael Borkon, MD & St Luke's Hospital, Kansas City, Mo \\
\hline Robert Kramer, MD & Maine Medical Center, Portland, Maine \\
\hline Ralph de la Torre, MD & Beth Israel Deaconess Medical Center, Boston, Mass \\
\hline Tirone David, MD & Toronto General Hospital, Toronto, Ontario, Canada \\
\hline John Sullivan, MD & Queen Elizabeth II Health Sciences Centre, Halifax, Nova Scotia, Canada \\
\hline Guy Fradet, MD & Vancouver General Hospital, Vancouver, British Columbia, Canada \\
\hline W. R. Eric Jamieson, MD & St. Paul's Hospital, Vancouver, British Columbia, Canada \\
\hline
\end{tabular}




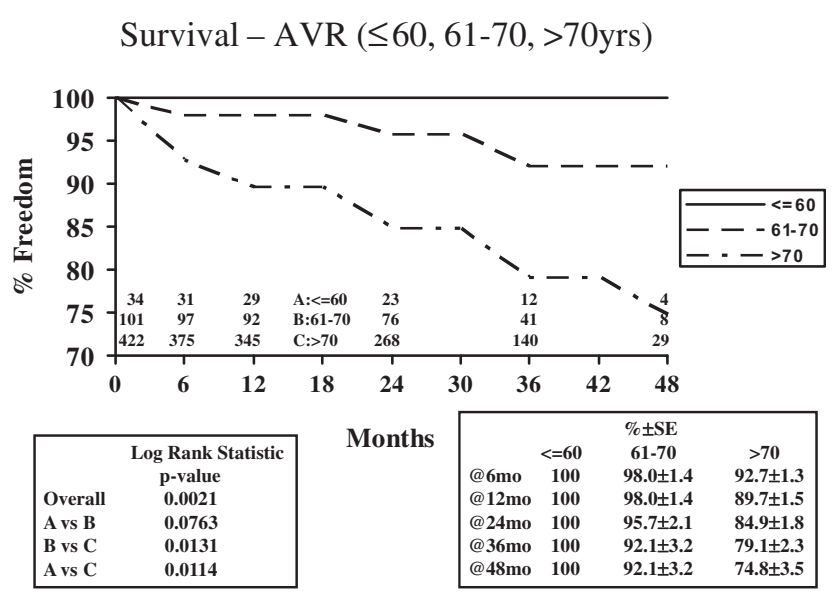

FIGURE E1. Patient survival AVR by age groups $(\leq 60,61-70,>70$ years). $A V R$, Aortic valve replacement; $S E$, standard error.
Hemodynamics for Aortic Valve Replacement at 6 months and 2 Years
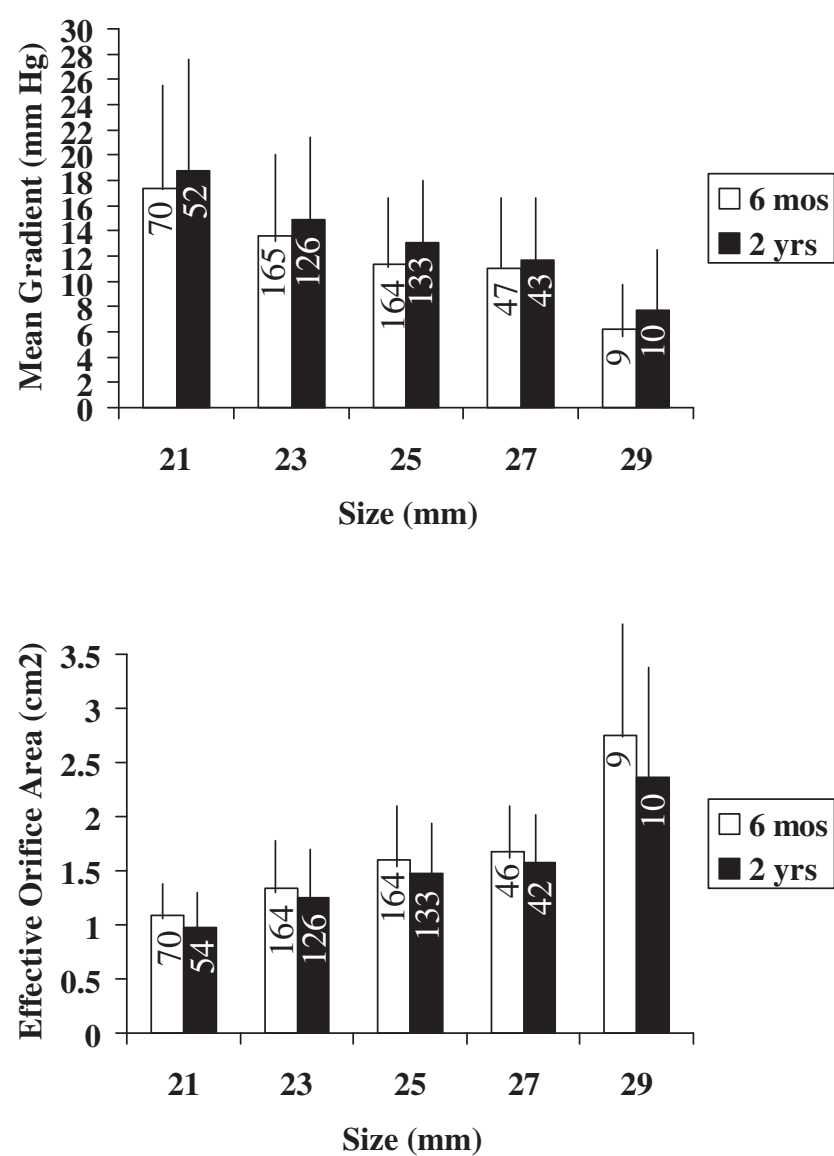

FIGURE E3. Hemodynamics—aortic valve replacement (mean gradients and effective orifice areas) at 6 months and 2 years.

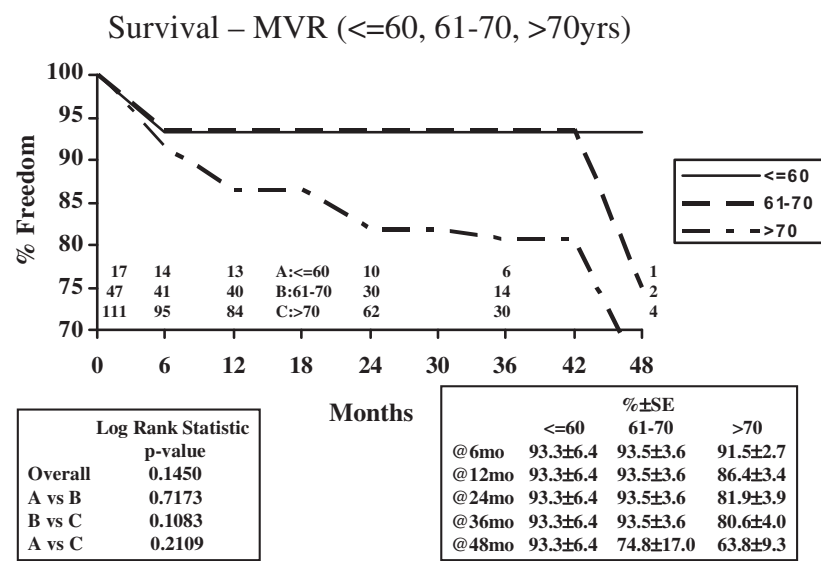

FIGURE E2. Patient survival MVR by age groups $(<60,61-70,>70$ years). $M V R$, Mitral valve replacement; $S E$, standard error. 
Hemodynamics for Mitral Valve Replacement at 6 months and 2 Years
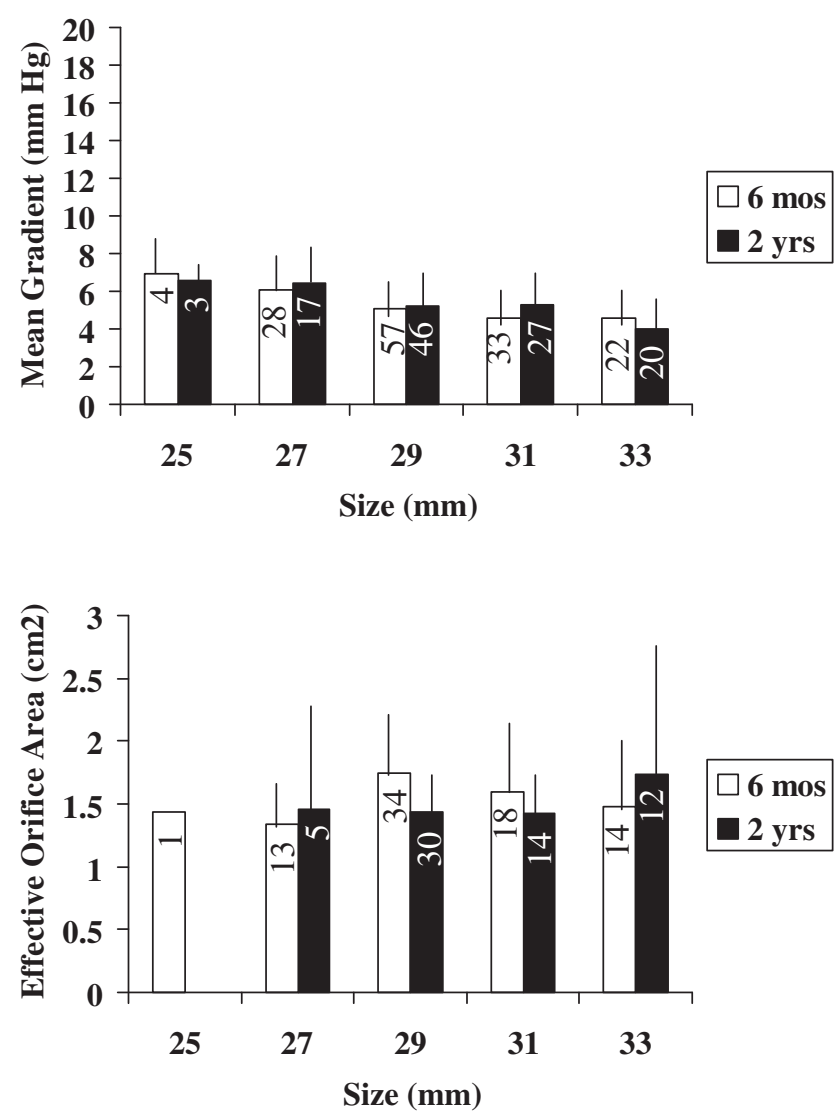

FIGURE E4. Hemodynamics—-mitral valve replacement (mean gradients and effective orifice areas) at 6 months and 2 years.

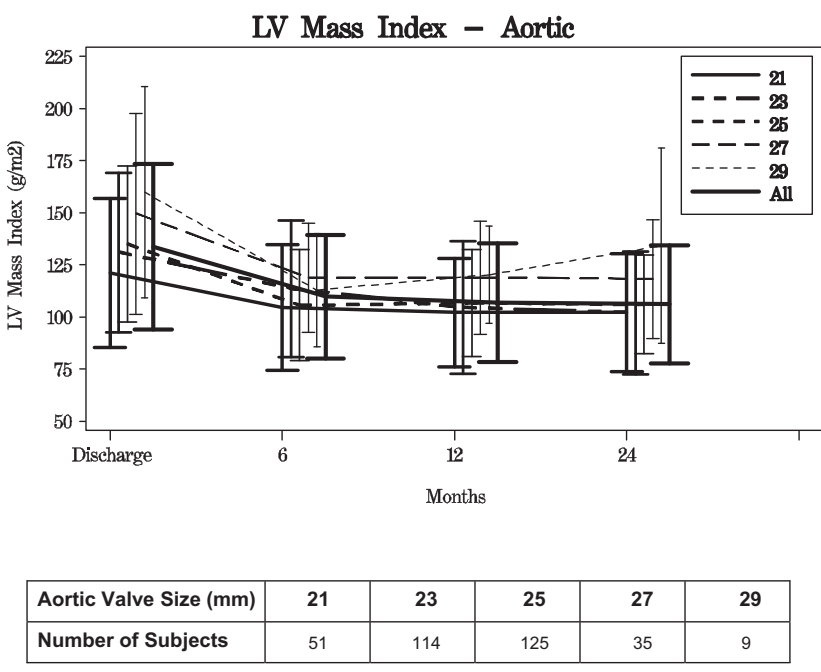

FIGURE E5. Left ventricular $(L V)$ mass regression. 